\title{
Review Paper \\ Parasitological, Immunological, and Molecular Methods in Diagnosis of Human Strongyloidiasis
}

\author{
Zohreh Fakhrie-Kashan ${ }^{1},{ }^{*}$ Meysam Sharifdini ${ }^{2}$ (1)
}

1. Department of Medical Parasitology and Mycology, School of Public Health, Tehran University of Medical Sciences, Tehran, Iran. 2. Department of Medical Parasitology and Mycology, School of Medicine, Guilan University of Medical Sciences, Rasht, Iran.

\begin{tabular}{|l|l}
\hline $\begin{array}{l}\text { Use your device to scan } \\
\text { and read the article online }\end{array}$ \\
Citation Fakhrie-Kashan Z, Sharifdini M. Parasitological, Immunological, and Molecular Methods in Diagnosis of Human Strongyloi- \\
diasis: A Review. The Journal of Qazvin University of Medical Sciences. 2020; 23(6):562-575. https://doi.org/10.32598/JQUMS.23.6.8 \\
doi https://doi.org/10.32598/JQUMS.23.6.8
\end{tabular}

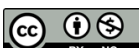

Received: 04 Dec 2018

Accepted: 21 Jan 2019

Available Online: 01 Feb 2020

Keywords:

Diagnosis, Strongy-

loides stercoralis, Hu-

man, Strongyloidiasis

\section{A B STRACT}

Strongyloidiasis is caused by intestinal nematode called Strongyloides stercoralis (S. stercoralis) which can lead to hyperinfection syndrome and disseminated infections. If not diagnosed and properly treated, it can even lead to death. The sensitivity of parasitological methods is not high enough and multiple stool sampling over consecutive days is essential to improve the detection rate. The agar plate culture method is more sensitive to the detection of S. stercoralis in fecal samples than other parasitological techniques. Serological tests have demonstrated higher sensitivity, but they have low specificity because of crossreactivity with other helminthes. Moreover, they are not helpful for follow-up of treatment, because they cannot distinguish between new and old infections. Recently, some Polymerase Chain Reaction (PCR)-based techniques have been developed for detection of S. stercoralis with high sensitivity and specificity. These methods are rapid but expensive and need well-equipped laboratories. In this paper, conventional and novel methods for laboratory diagnosis of strongyloidiasis are reviewed.

\section{Extended Abstract}

\section{Introduction}

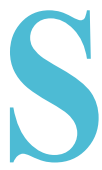

trongyloidiasis caused by intestinal nematode called Strongyloides stercoralis which is one of the most important neglected soiltransmitted helminth infections. This nematode is mostly found in tropical and temperate countries with poor sanitation standards; however, it has been increasing in non-endemic countries due to migration and travel [1]. The clinical presentation of strongyloidiasis is variable from asymptomatic infections to gastrointestinal, cutaneous, or pulmonary manifestations [1]. In immune-suppressed patients, chronic strongyloidiasis may lead to hyperinfection syndrome or disseminated infections
[2]. With the increasing number of immunocompromised patients in the last decade, severe complicated strongyloidiasis has become a major health problem to such patients [2]. There is no definitive gold standard for the diagnosis of strongyloidiasis [3]. Therefore, reliable diagnostic techniques are needed for this purpose in at-risk people in order to decrease the mortality and morbidity rate. The aim of this study was to review the parasitological, immunological and molecular methods developed for the diagnosis of strongyloidiasis.

\section{Materials and Methods}

The search was conducted in a number of valid databases including PubMed, ScienceDirect, Scopus, Iran-

\section{* Corresponding Author:}

Meysam Sharifdini

Address: Department of Medical Parasitology and Mycology, School of Medicine, Guilan University of Medical Sciences, Rasht, Iran

Tel: +98 (13) 33690884

E-Mail: sharifdini@gums.ac.ir 
Medex, and Google Scholar. A total of 63 relevant papers were selected for review.

\section{Results}

Many parasitological methods usually rely on the detection of larvae in stool samples, such as formalin ether concentration, Baermann apparatus, Harada-Mori culture, and nutrient agar plate culture [4]. Most of parasitological techniques are insensitive, because the release of larvae is usually low and irregular in fecal samples especially in chronic infections [1]. Several studies have shown that agar plate culture is more sensitive than other techniques in the detection of $S$. stercoralis larva in fecal samples [5-7]. However, this technique is labor-intensive and time-consuming and requires multiple fresh stool samples and skillful individuals $[4,5]$.

Several immunological methods such as indirect agglutination test, Enzyme-Linked Immunosorbent Assay (ELISA), Indirect Immunofluorescence Assay (IFA), and dipstick test have been developed with different sensitivity and specificity depending on the used antigen and immunoglobulin isotopes [8-10]. Overall, immunodiagnostic methods have higher sensitivity than conventional parasitological methods [11]. The gelatin particle indirect agglutination test is a simple, rapid, and sensitive method with no need for any specialized equipment. This method is useful for the mass-screening of strongyloidiasis [12]. The IFA test is useful for the diagnosis of strongyloidiasis by detecting antibody in the serum of patients; however, there are some difficulties in obtaining $S$. stercoralis antigens in addition to the risk of contamination, but using other species of Strongyloides can be helpful for immunological diagnosis [11]. This technique has high sensitivity and specificity with minimal cross-reactivity with other helminthic infections. It has the advantage of determining antibody titers that can help in following up on treatment process. Another use of this technique is in epidemiological studies among at-risk people in endemic areas [11].

The ELISA method is extremely useful and considered to be superior to other serological tests regarding its high level of sensitivity for the diagnosis of strongyloidiasis. This technique has been widely used for the diagnosis of S. stercoralis infection worldwide, but one of its important disadvantages is the possibility of immunological crossreactivity with other helminthic infections [11, 13]. A major drawback to ELISA-based diagnosis is a reliance on crude extract antigen preparation which is time-consuming and needs larvae extraction from humans or experimental animals. IgG avidity ELISA can be useful in differentiating chronic infections from acute, past, and present infections.
Another important advantage of this technique is its application in monitoring the reduction of antibody titers after treatment [11, 13]. Van Doorn et al. (2007) showed that dipstick assay has a high level of accuracy for the diagnosis of strongyloidiasis, and has important features such as practicality, simplicity and using a small number of antigens [14].

Molecular methods have shown different results in detection of S. stercoralis DNA in stool samples. The method of DNA extraction is an important key factor for increasing the sensitivity of DNA-based techniques [11]. In a study carried out by Repetto et al. (2013), an In-House DNA extraction method based on efficient lysis of larvae and removal of inhibitors in the stool samples was introduced [15]. Moghaddassani et al. (2011) developed single and nested Polymerase Chain Reaction (PCR) methods for specific detection of $S$. stercoralis DNA in stool samples but sensitivity of the single PCR was higher than that of nested PCR [16]. Among DNA-based techniques, real-time PCR targeting the $18 \mathrm{~S}$ ribosomal RNA gene of $S$. stercoralis described by Verweij et al. (2009) has been shown to be a sensitive and specific method [17]. Sharifdini et al (2015) tested both nested and real-time PCR in comparison with parasitological methods (agar plate culture and formalin ether concentration) for the detection of $S$. stercoralis in fecal samples. In their study, molecular methods were superior to parasitological methods and nested PCR was more sensitive than real-time PCR [7]. Recently, Lodh et al. (2017) showed that DNA amplification from urine is significantly more sensitive than stool examination techniques [18].

\section{Discussion}

Human strongyloidiasis is a major neglected intestinal helminthiasis which is considered as an important cause of morbidity and mortality in immunocompromised patients. Therefore, early diagnosis and treatment of S. stercoralis infection, when it is still in the chronic phase, is necessary [1]. Parasitological methods are not sufficiently sensitive to detect strongyloidiasis due to the irregular release of larvae in feces [1]. The agar plate culture has been recognized as a more sensitive method than other parasitological techniques $[5,6]$. Immunodiagnostic methods have demonstrated higher sensitivity and lower specificity, because of cross-reactivity with other helminthic infections. They are useful for screening the high-risk patients but not helpful for the follow-up of treatment [11]. Recently, molecular techniques have been developed for the detection of $S$. stercoralis with high sensitivity and specificity. These methods are rapid but expensive and need well-equipped laboratories [13]. 


\section{Ethical Considerations}

Compliance with ethical guidelines

This is a review study. No experiments were conducted on human or animal samples.

Funding

This research did not receive any specific grant from funding agencies in the public, commercial, or not-forprofit sectors.

Authors' contributions

Investigation, resources, and writing: Zohreh FakhrieKashan; Editing, review, and project administration: Meysam Sharifdini.

Conflicts of interest

The authors declared no conflicts of interest.

Acknowledgements

The authors would like to thank Prof. Eshrat Beigom Kia (Faculty member, Tehran university of medical sciences, Iran) for her help and support. 
مرورى بر روشهاى انتَلشناسى، ايمونولوزيك و مولكولى در تشخيص استرونثريلوئيديازيس

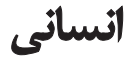

\author{
زهره فخريه كاشان'? "•ميثم شريف دينى
}

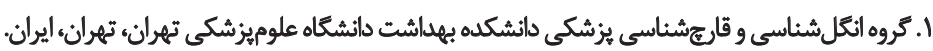

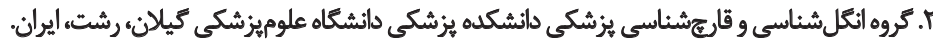

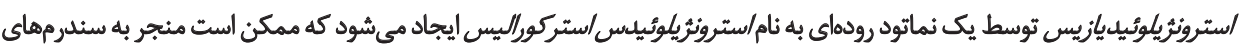

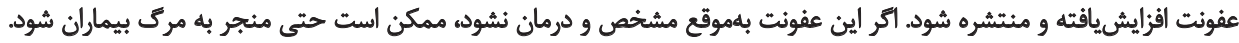

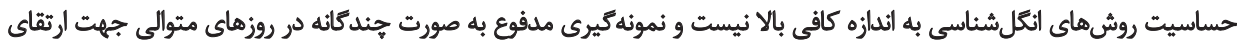

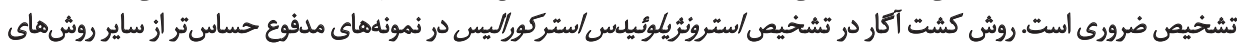

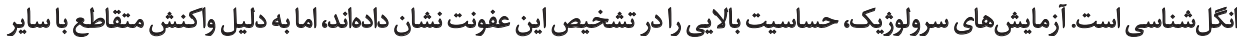

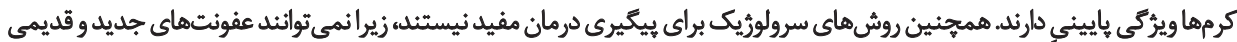

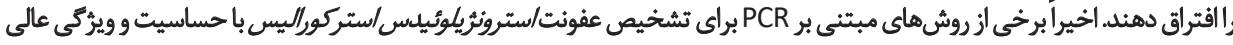

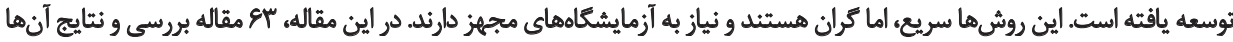

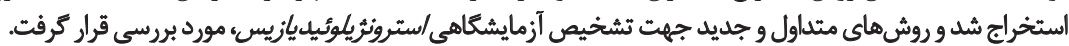

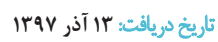

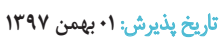

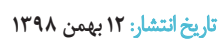

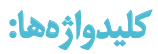

تشخيص:

استرونتئيوئيسنس

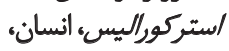
استروتريلؤيليديازيس انسان

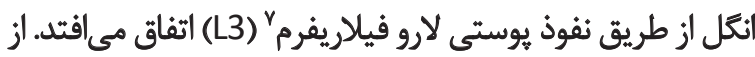

مقلمه

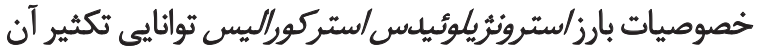

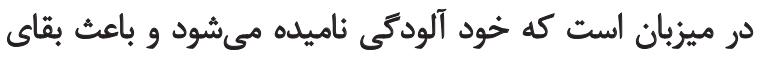

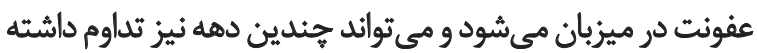

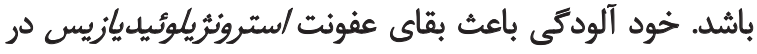

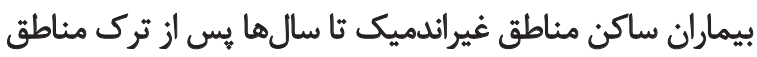

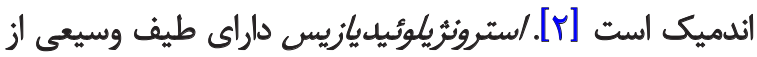

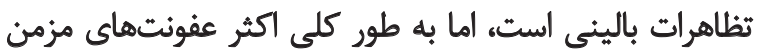

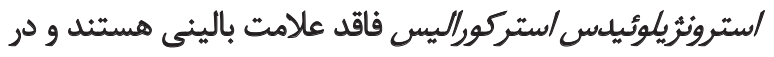

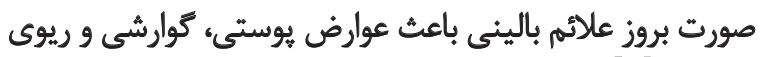

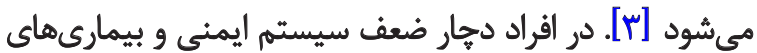

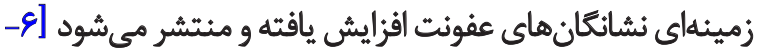

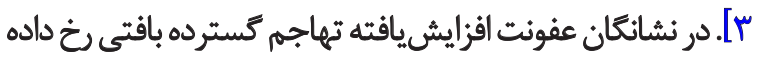

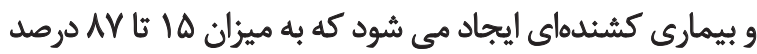

$$
\text { موجب مركومير ميشود ايجاد مي شود. }
$$

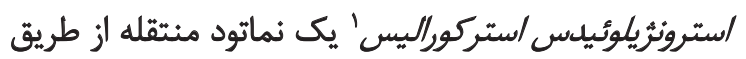

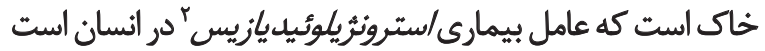

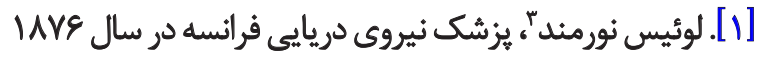

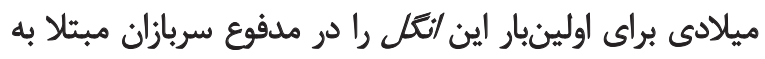

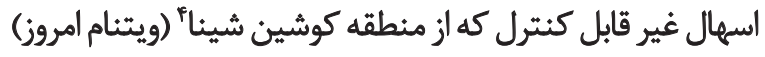

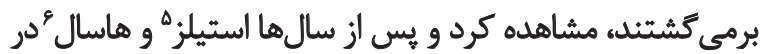

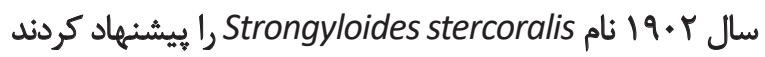

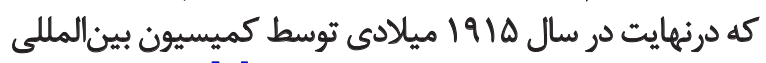

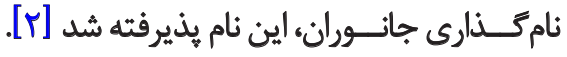

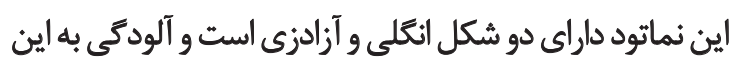

\section{Strongyloides stercoralis}

2. Strongyloidiasis

3. Louise normand

4. Cochin China

5. Stiles

6. Hassal

ㅁ.

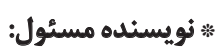

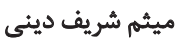

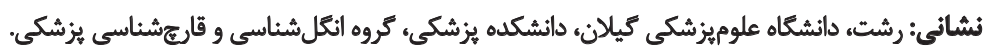

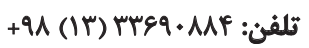

$$
\begin{aligned}
& \text { راياثامه: sharifdini@gums.ac.ir }
\end{aligned}
$$


درباره روشهاى تشخيصى رايج و نوين انكل شناسى، سرولوزى و ورئ

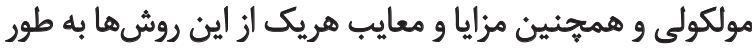
مختصر بحث خواهد شد.

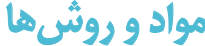

در اين مطالعه مرورى، باه مقاله ثبتشده در يايكاههاى

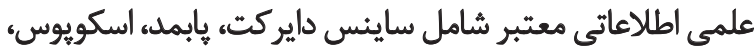

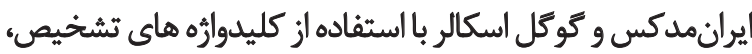

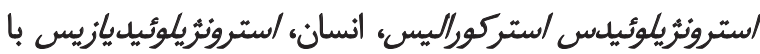

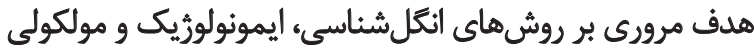

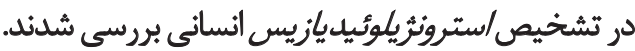

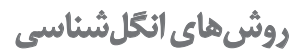

\section{كسترش مرطوب (مستقيم)}

كسترش مستقيم مدفوع سادهترين و ارزانترين روش

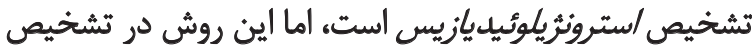

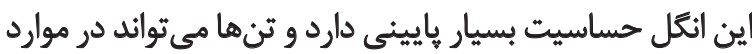

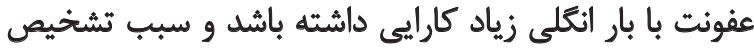

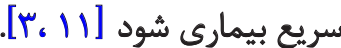

\section{روش رسوبى فرمالين ـاتر}

روش فرمالين - اثتر جهت تشخيص كيست تكياختهها،

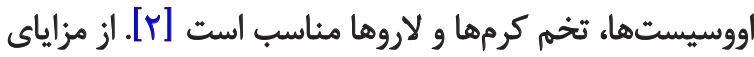

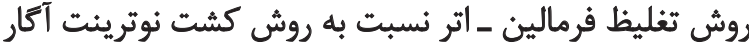

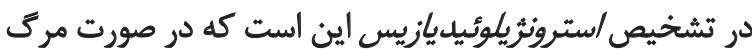

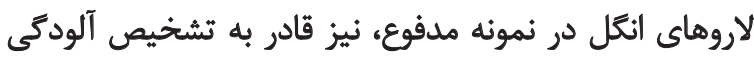

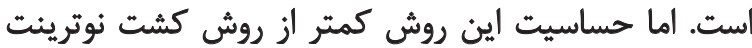

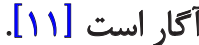

بر اساس مطالعات انجامكرفته در زمينه تشخيص

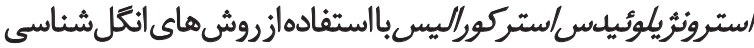

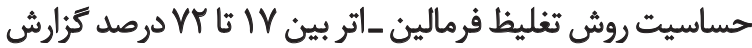

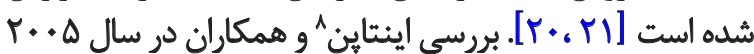

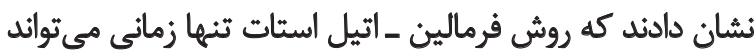

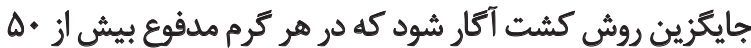

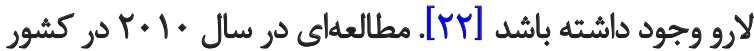

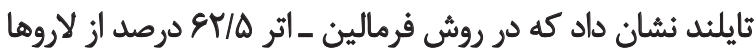

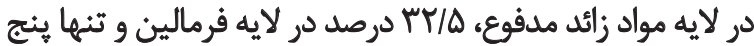

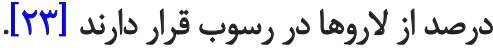

$$
\text { روش كشت آكار }
$$

كشت مدفوع در نوترينت آكار حساسترين روش انكل شناسى براى
استرونثيلوئيلس /ستركوراليس در مناطق ترمسيرى و

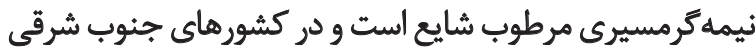

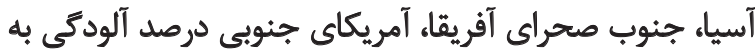

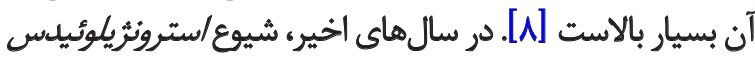

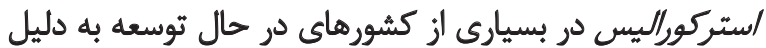

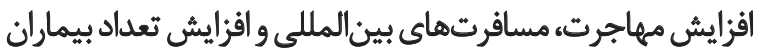

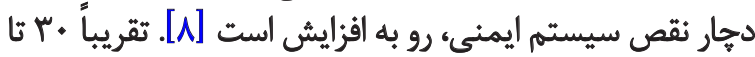

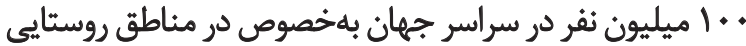

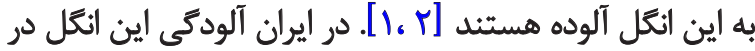

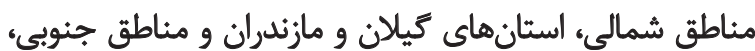

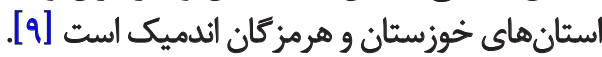

در مطالعه اشرفى و همكاران م. P. درصد از افراد داراى

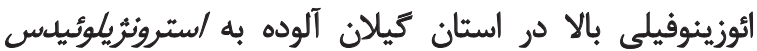

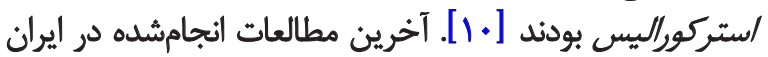

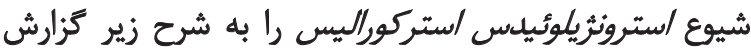

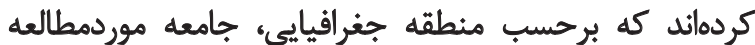

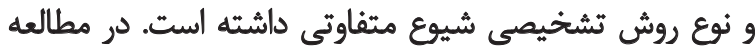

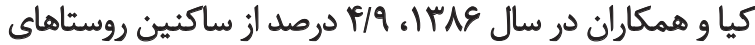

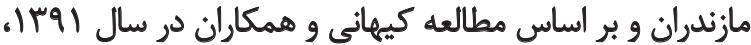

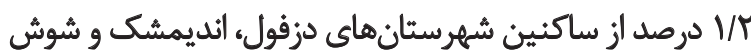

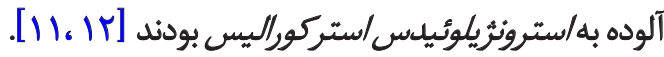

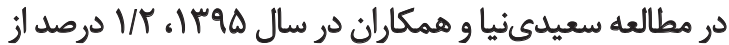

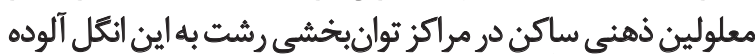

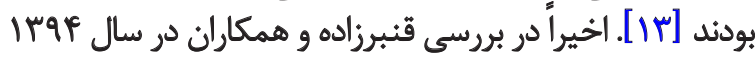

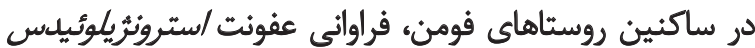

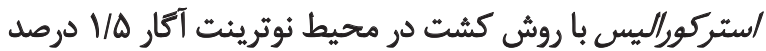

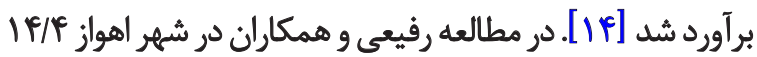

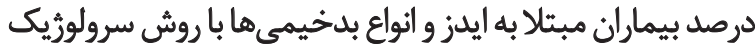

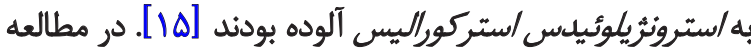

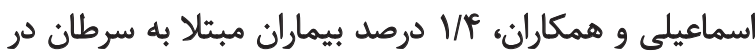

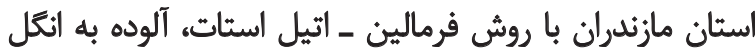
استرونزئوئيليس بودند [19]. روشهاي تشخيص آزمايشعاهى /سترونريلوئيديازيس عمدناً

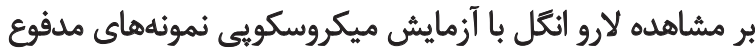

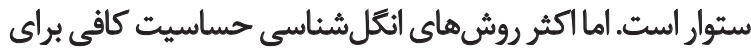

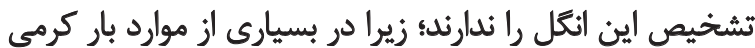

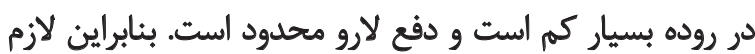

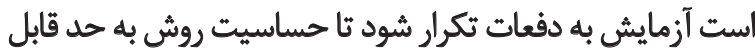

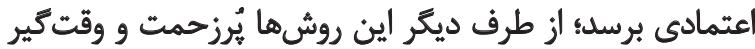

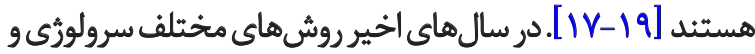

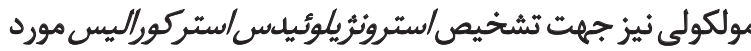

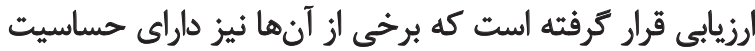

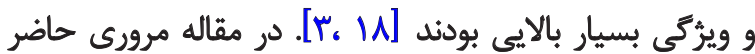


استركوراليس به اندازه كرمهاي قلابدار نيست. در اين روش ابتدا

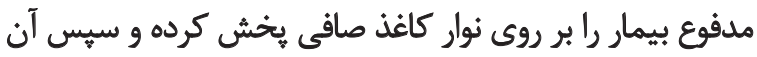

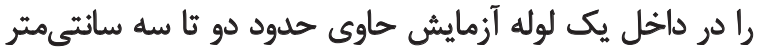

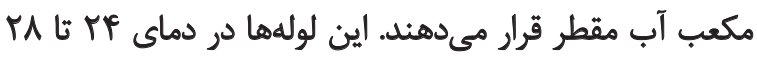

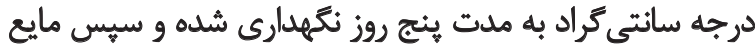

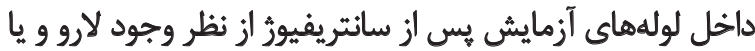

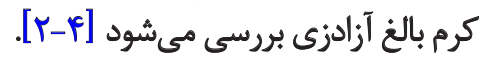

كشت روى زغال هوب

در اين روش ه تا • إخرم از مدفوع را به شكلى با زغال مخلوط

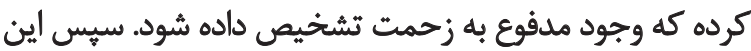

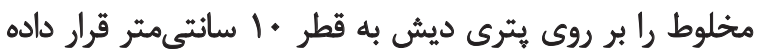

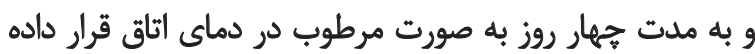

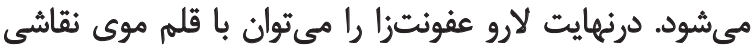

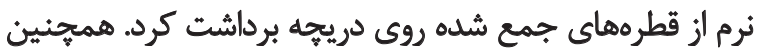

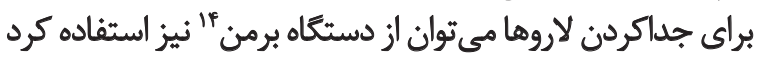

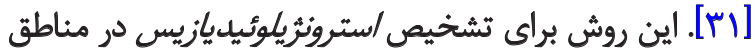

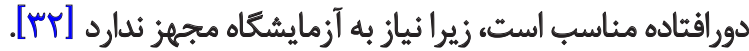

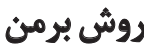

با استفادهاز اين روش مي توان لارو مرحله اول/ستروتئريلوئيلس

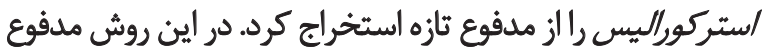

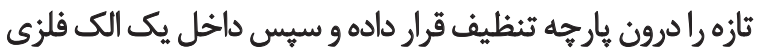

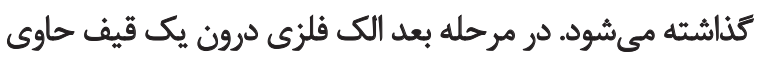

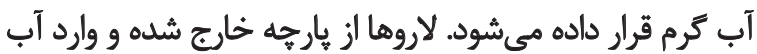

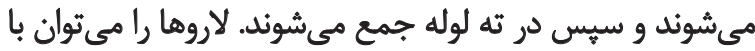

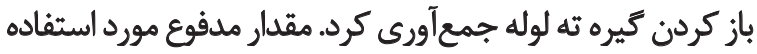

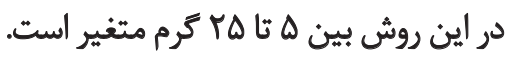

استفاده از مقدار بيشتر مدفوع باعث افزايش حساسيت اين

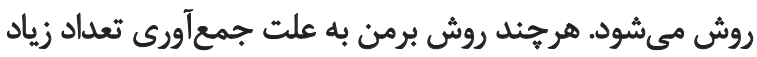

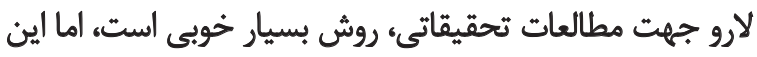

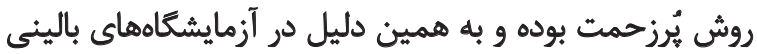

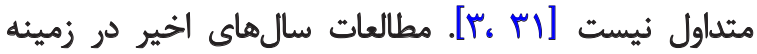

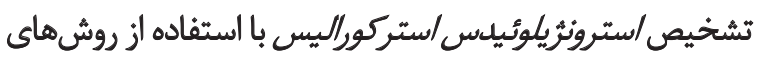

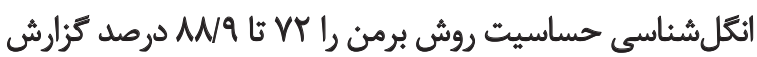

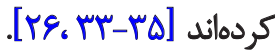

\section{آزمايش محتويات دوازدهه}

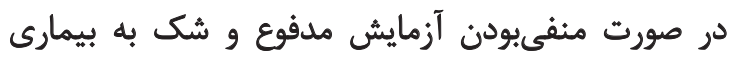

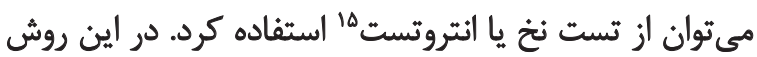
تمام اشكال انكل (لارو، تخم و كرم بالغ) را مى توتوان در نمونه

14. Baerman apparatus

15. Entero test

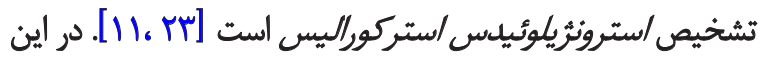

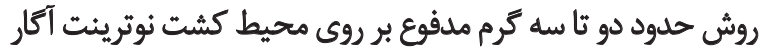

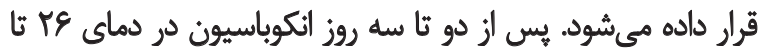

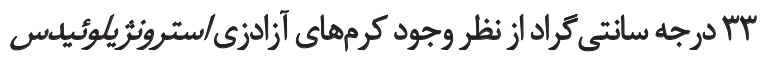

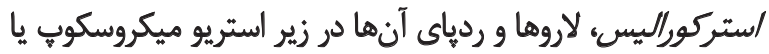

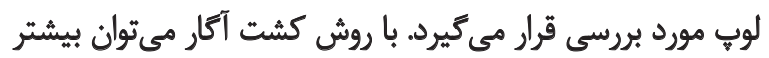

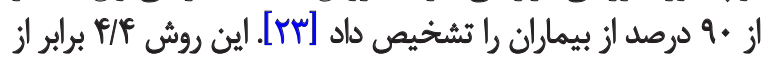

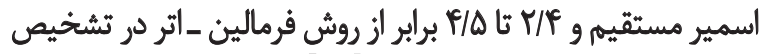

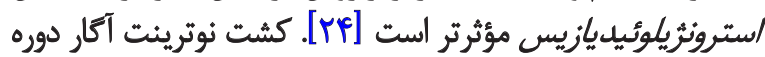

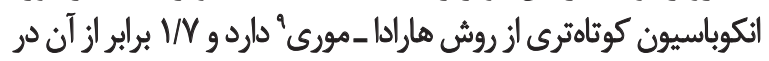

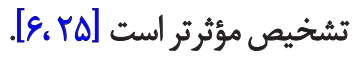
مطالعات مختلف نشان دادند كه حساسيت روش كشت

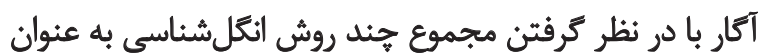

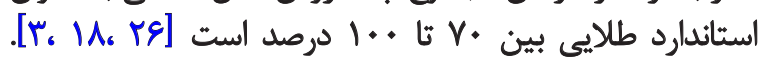

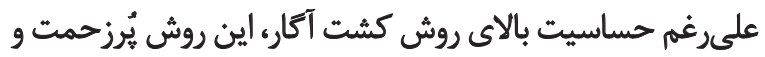

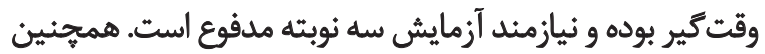

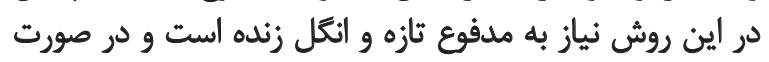

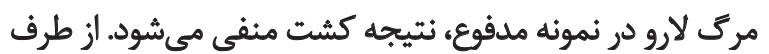

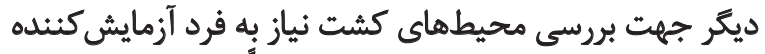

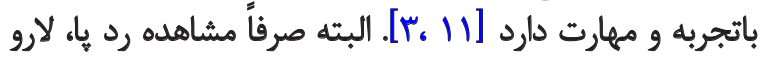

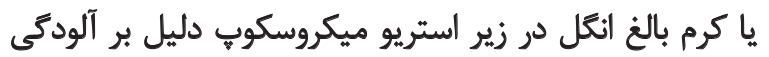

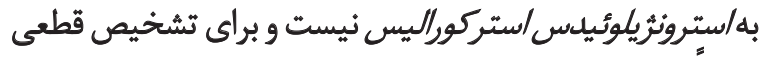

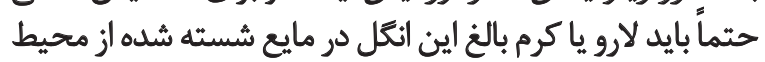

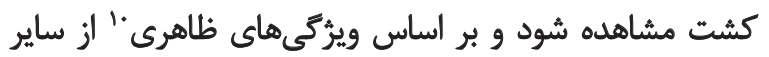

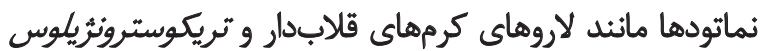

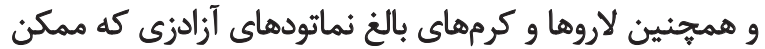

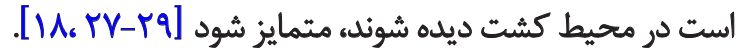
سيلويا" و همكاران روش كشت آكار را جهت تشخيص

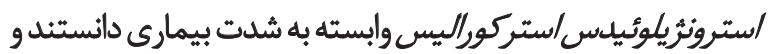

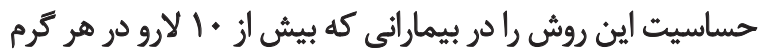

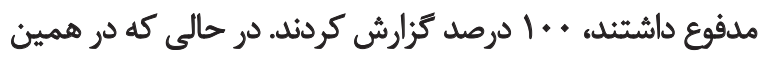

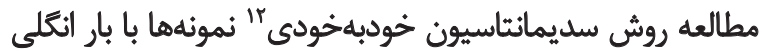

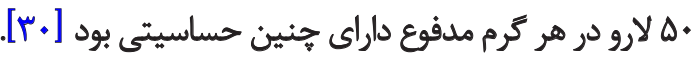

$$
\text { روش هارادا ـ-مورى }
$$

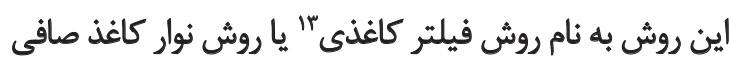

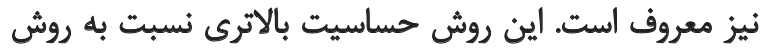

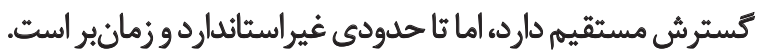

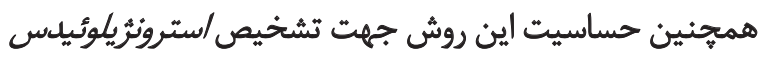


تست أكلوثيناسيون توسط ذرات زلاتين

ساتو “و همكاران در سال 1991 روش آكلوتيناسيون ذرات

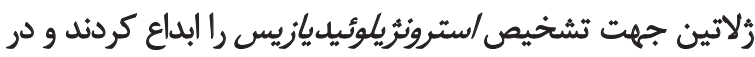

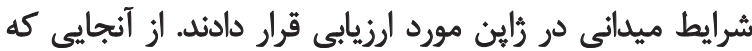

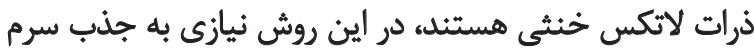

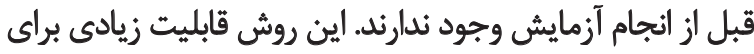

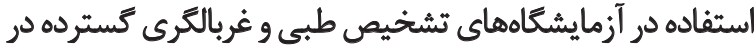

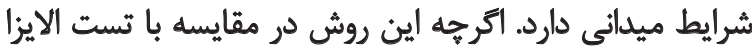

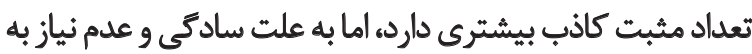

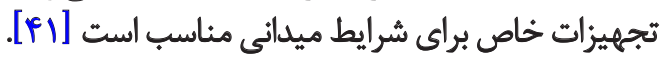

$$
\text { تست ايمونوفلور سانس غير مستقيم }
$$

روش ايمونوفلورسانس غيرمستقيم" از نظر تكنيكى از الايزا

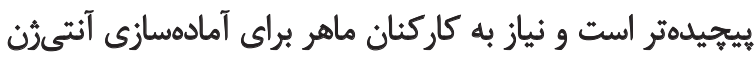

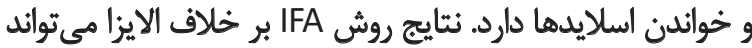

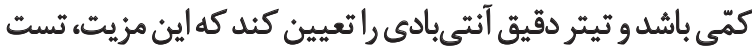

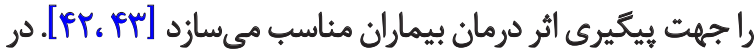

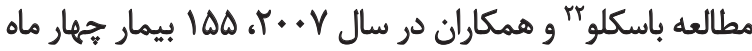

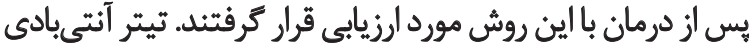

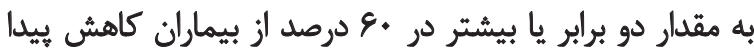

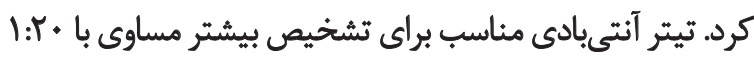

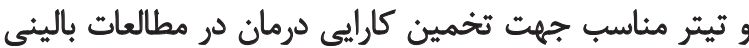

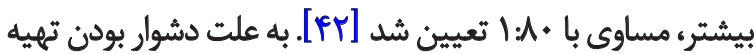

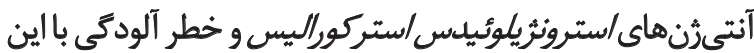

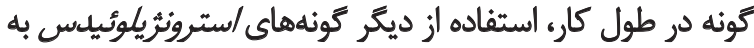
تشخيص ايمونولوزيك عفونت كمك مى كند الند [FF]

استفاده ديكر از اين روش، كاربرد آن در بررسى إيدميولوئوريك

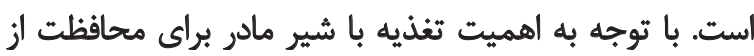

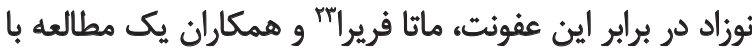

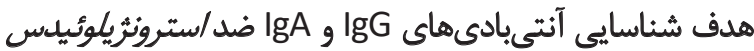

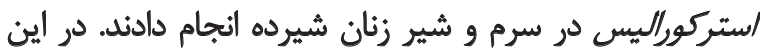

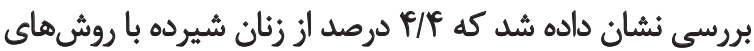

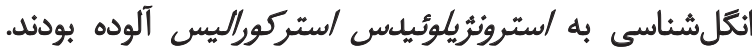

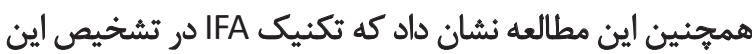

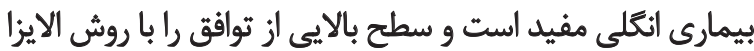

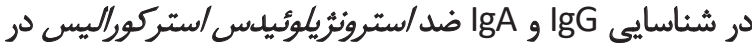

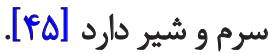

تست ايمونوفلورسانس با استفاده از برش هاى كرايو ميكروتوم

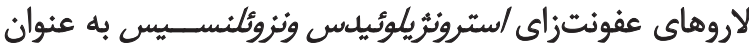

بلدستآمده مشاهده كرد. براى انجام اين آزمايش بيمار يك

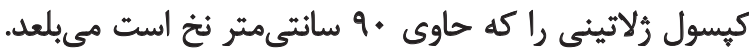

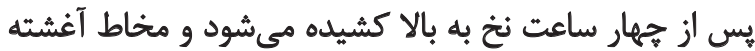

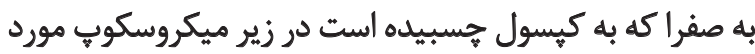

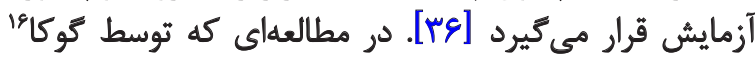

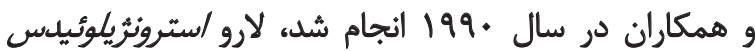

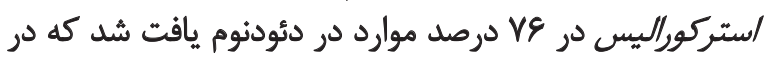

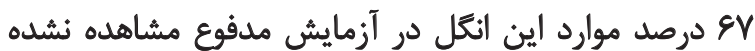

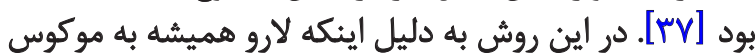

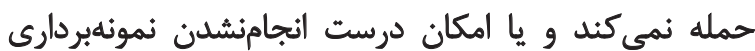

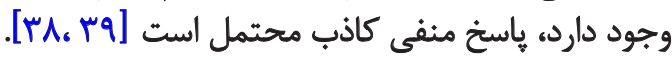

\section{بررسى مايعات و بافتهاى بدن}

كاهى لارو را مىتوان در نمونه خلط، بيويسى از روده،

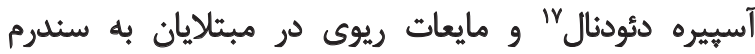

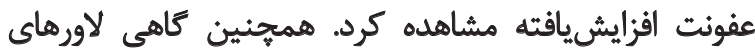

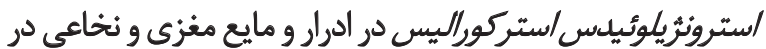

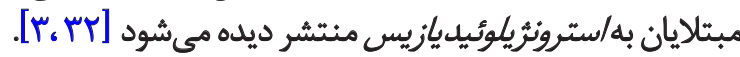

$$
\text { روش هاي ايمنى شئاشتى }
$$

تاكنون روشهاي ايمنىشناختى متنوعى بر اساس تجسس

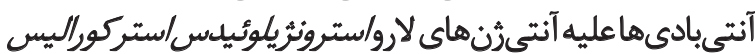

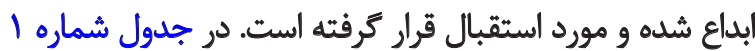

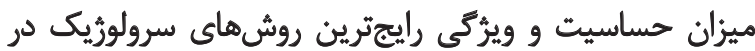
مطالعات اخير نشان داده شده است.

$$
\text { تست يوستى }
$$

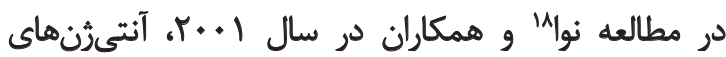

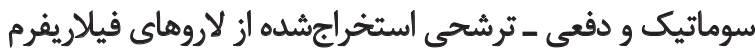

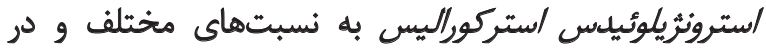

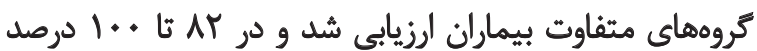

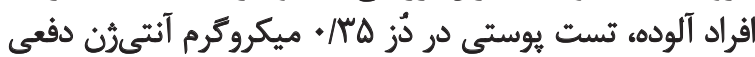

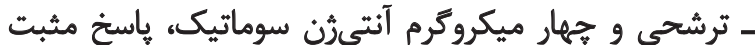

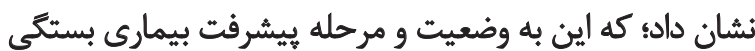

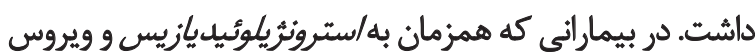

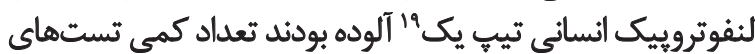

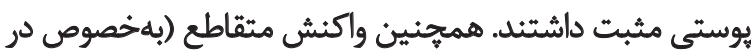

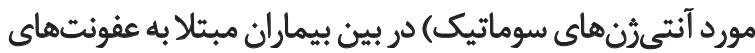

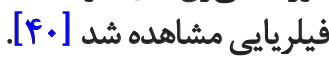

16. Goka

17. Aspiration of duodenum

18. Neva

19. Humans t-lymphotropes virus 1 (HTLV-1) 


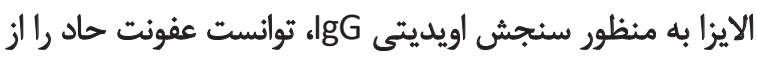

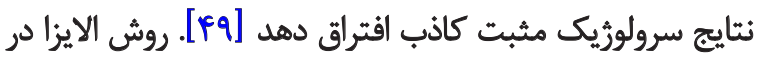

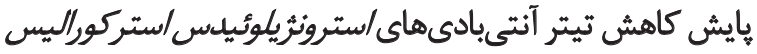

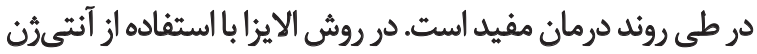

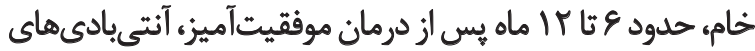

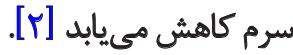

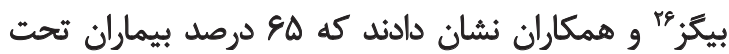

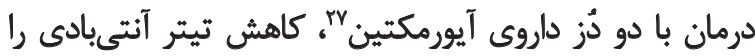

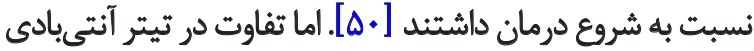

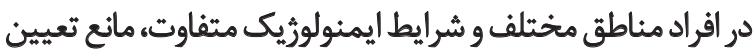

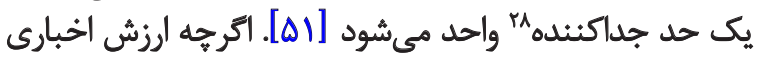

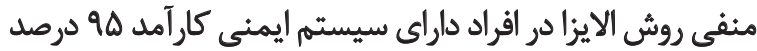

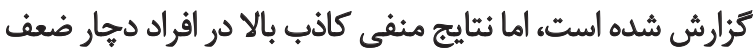

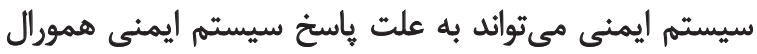

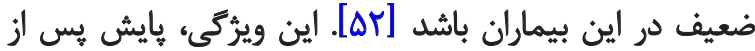

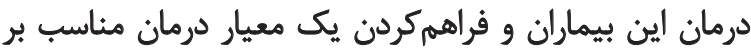

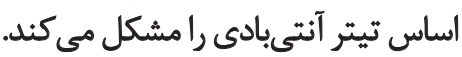

البدرى

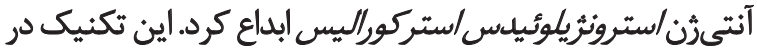

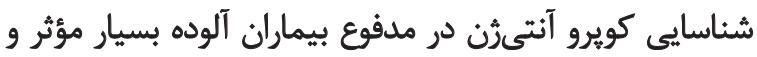

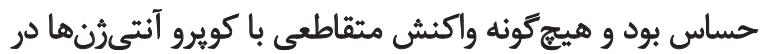

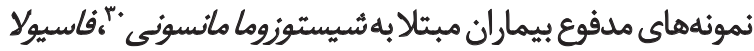

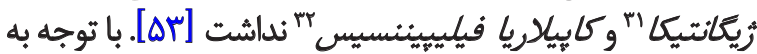

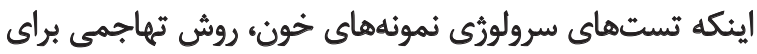

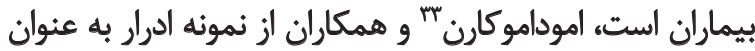

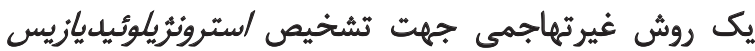

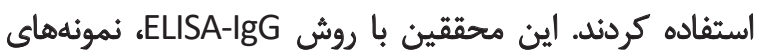
ادرار بيماران را با حساسيت

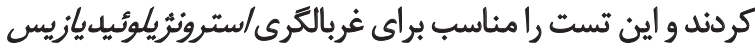
مناطق اندميك معرفى كردند [DF]

ووشي ديب اسثيك

تاكنون مطالعات كمى جهت تشخيص /سترونثيلوئيليازيس

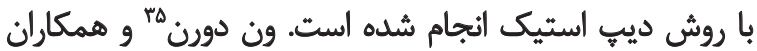

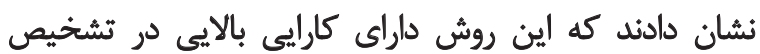

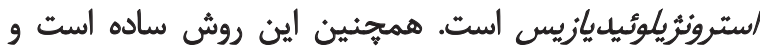

\section{Biggs}

27. Ivermectin

28. Cut off

29. El-Badry

30. Schistosoma manson

31. Fasciola gigantica

32. Capillaria philippinensis

33. Eamudomkarn

34. Dipstick

35. Van Doorn
آنتىرن ميتواند به عنوان يك روش كمكي براى تشخيص

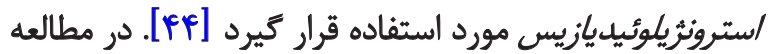

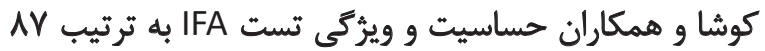

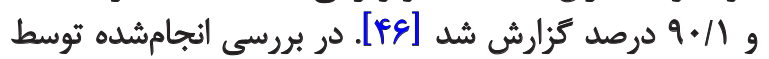

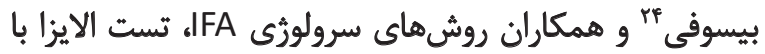

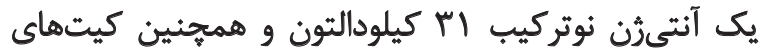

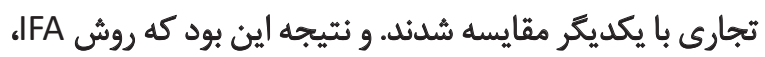

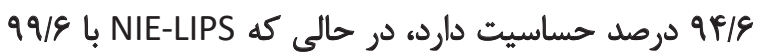

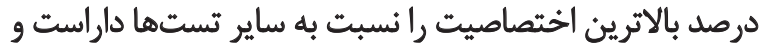

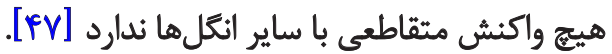

روث الايزاً

امروزه تست الايزا جهت تشخيص استرونزيلوئيديازيس به تورديه

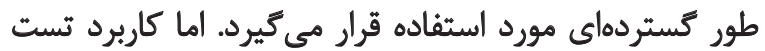

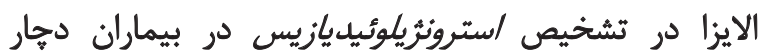

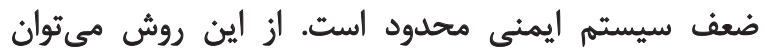

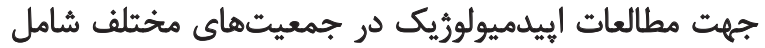

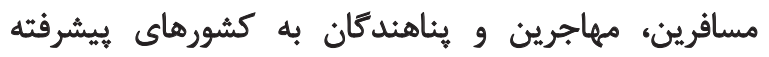

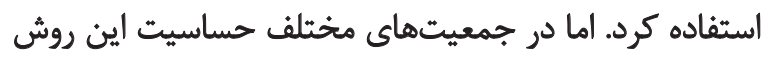

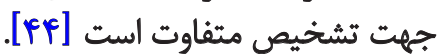

به منظور تشخيص آنتىباديهاي ضد استرونزيلوئيلس

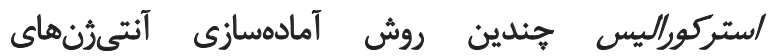

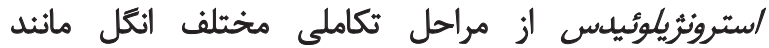

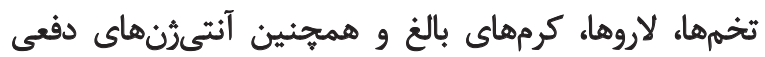

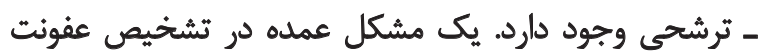

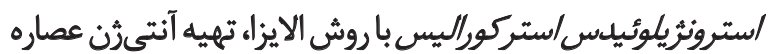

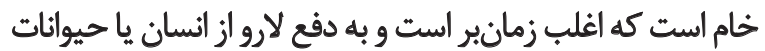

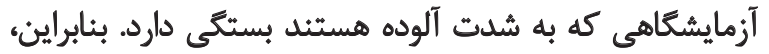

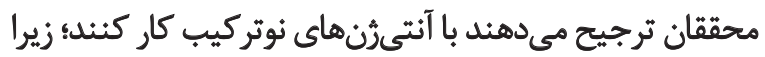

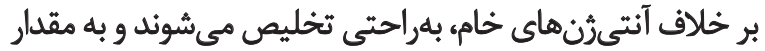

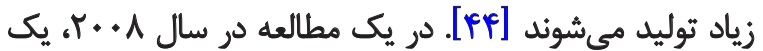

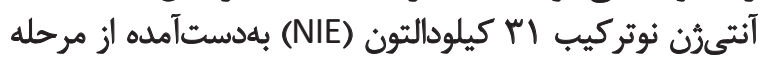

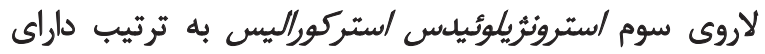

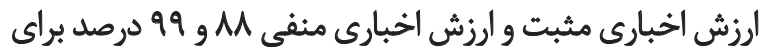

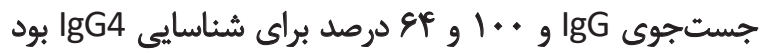

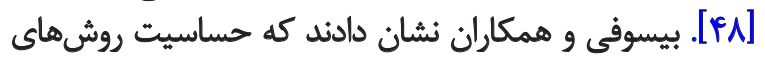

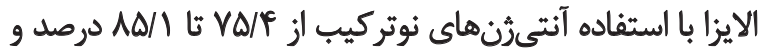

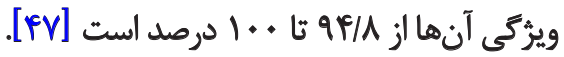
يكى از تكنيكهاى مفيد الايزا جهت افتراق عفونت حاد از

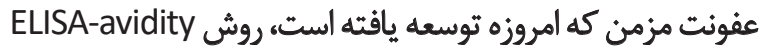

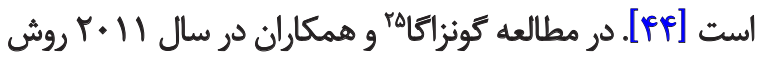




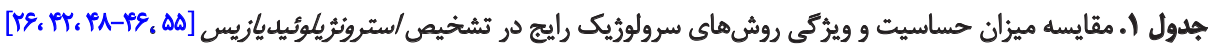

\begin{tabular}{|c|c|c|c|}
\hline مرجع & ويؤكى (درصد) & حساسيت (درصد) & نوع روش سرولوزيكي \\
\hline$[Y, F, F, F, F]$ & $A Y / P-Q W P$ & $n / 1-9 \vee / 5$ & IFAT \\
\hline 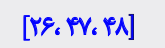 & $91 / 1-1 .$. & $V \cdot / A-9 V$ & NIE-ELISA \\
\hline$[Y, P, Y, F]$ & $19 / 1-1+$. & $A F / A-9 V / \Lambda$ & NIE-LIPS \\
\hline$[Y, F, Q \Delta D]$ & $9 / / 7-9 V / F$ & $M q q-q Y / T$ & IVD-ELISA \\
\hline$\left[P V_{c} \Delta \Delta\right]$ & $91 / 1-97 / 5$ & $A F / M-9 . / 1$ & Bordier ELISA \\
\hline
\end{tabular}

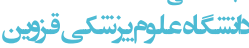

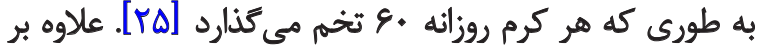

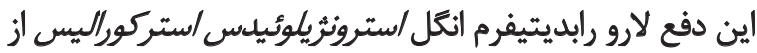

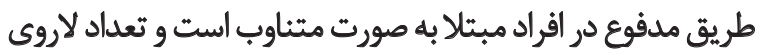

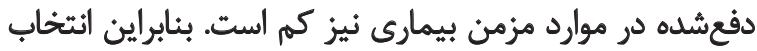

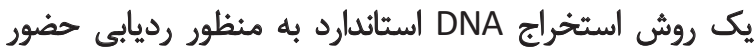

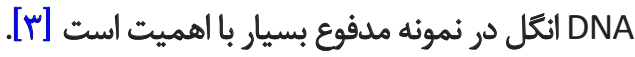

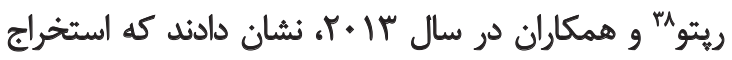

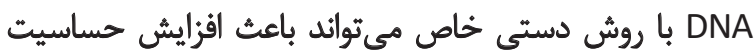

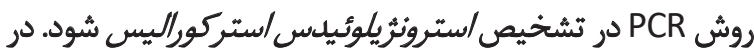

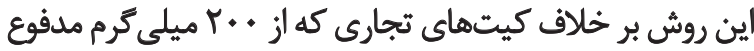

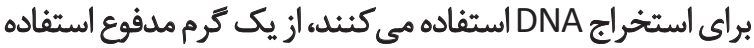

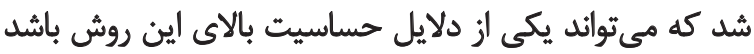

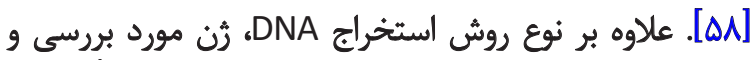
نوع روش مولكولى نيز در ميزان حساسيت اين روش نها تأثير كذار

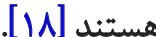

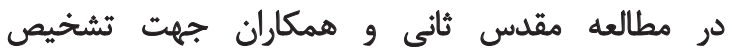

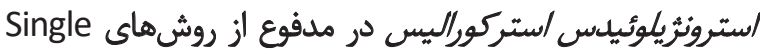

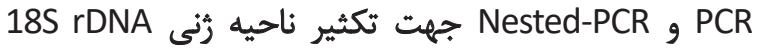

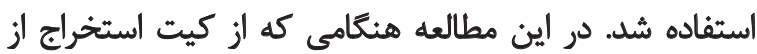

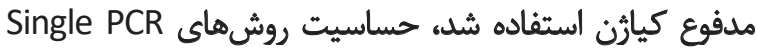

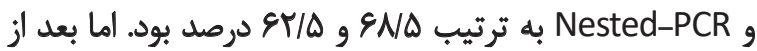
تغليظ نمونه مدفوع با روش اسيد ـاتر و سيس استخراج

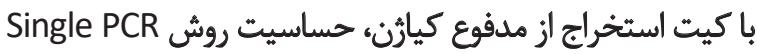

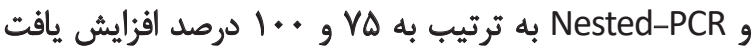

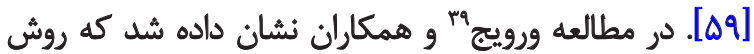
Real-time PCR

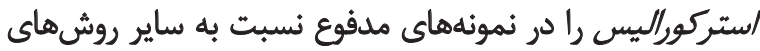

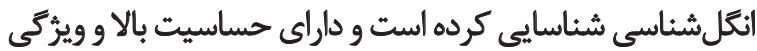

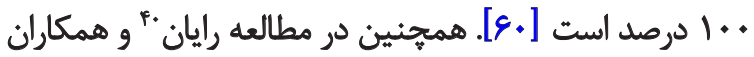

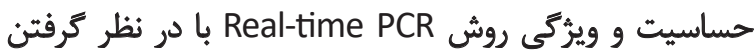

نياز به مقدار كم آنتىثن دارد؛ اما با اين حال اين روش نياز به

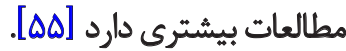

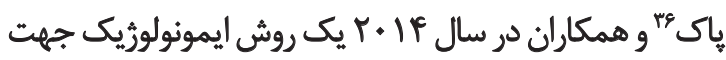

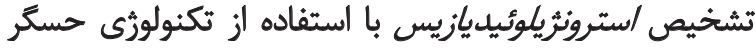

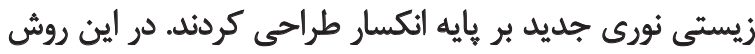

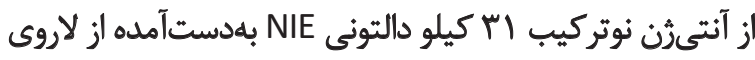

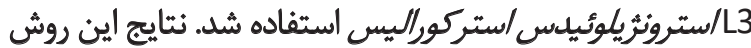

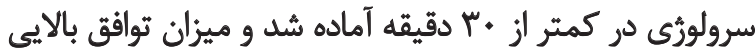

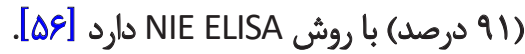

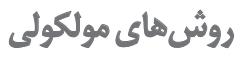

در سالهاى اخير استفاده از روشهاى مختلف مولكولى

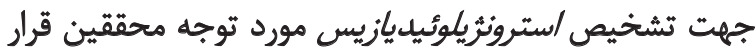

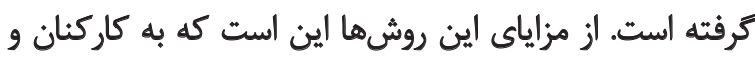

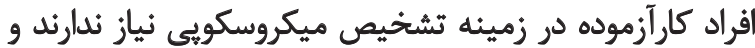

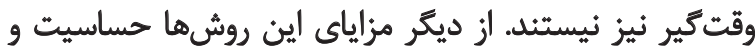

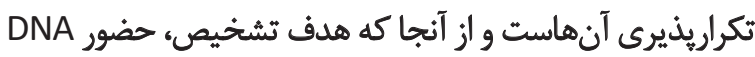

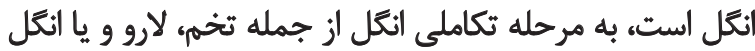

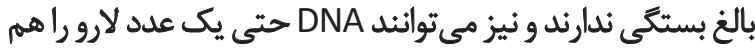

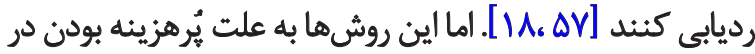

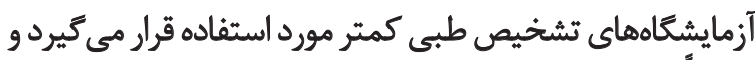

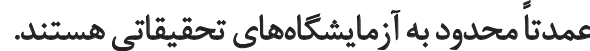
ثاكنون از روشهاى مولكولى همانند PCR Nested PCR، Real-timePCR

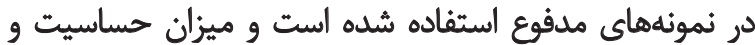

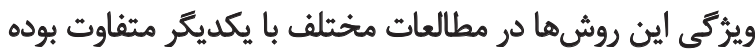

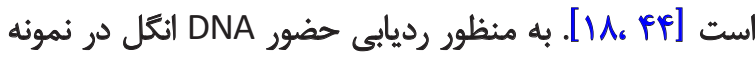

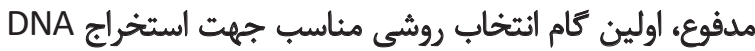

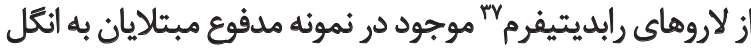

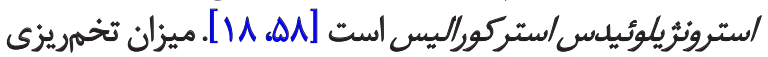
كرم ماده انكلى استرونريلوئيدس استركوراليس بسيار كم است؛ 


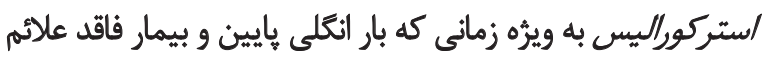

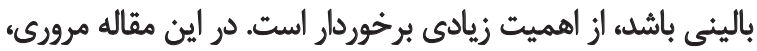

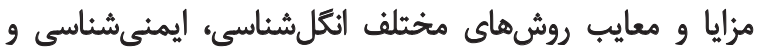

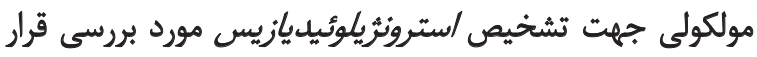
كرفته است كه به طور كلى عبارتاند ازئ

1. بيشتر روشهاى انتل انشناسى حساسيت لازم راجهت تشخيص

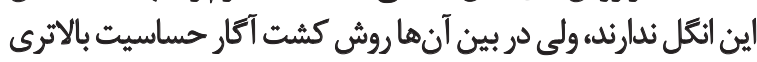

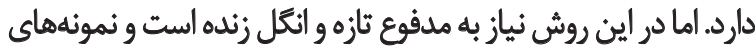

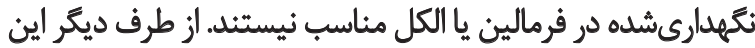

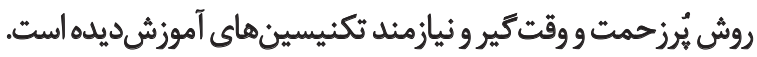

r. روشهاى ايمنىشناختى بهخصوص روش الايزا داراى

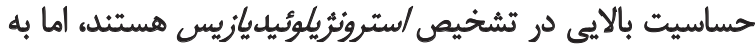

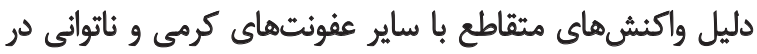

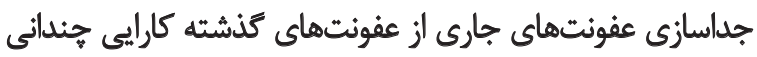

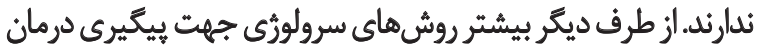

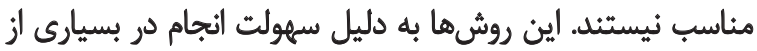

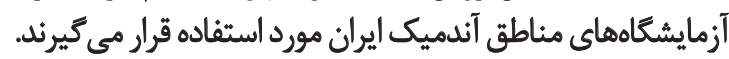
ب. امروزه استفاده از روشهاى مولكولى جهت تشخيص

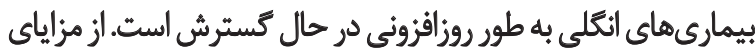

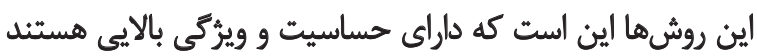

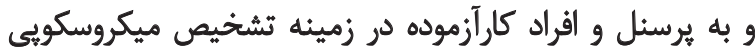

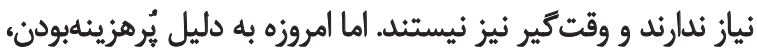

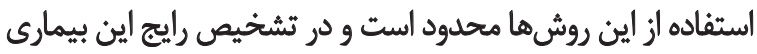

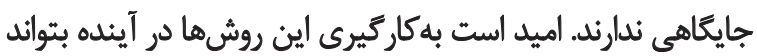

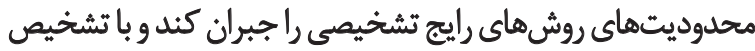

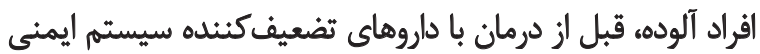

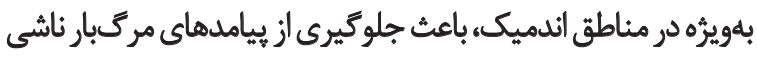

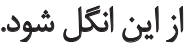

\section{مالاجظاتم اخلاقي}

\section{ييروى از اصول اخلاق يُوهش}

باتوجه به نوع مطالعه، نيازى به كد اخلاق نبوده است.

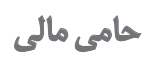

اين تحقيق هيج كمك مالى خاصى از سازمانهاي تأمين مالى ني

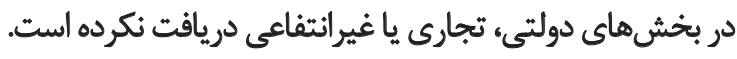

$$
\text { مشاركت نويسند مكان }
$$

جستوجو و جمعآورى منابع و نكارش: زهره فخريه كاشان؛ مديريت برورثه و ويرايش نهايى مقاله: ميثم شريفدينى زهره فخريه
روش هاى انتُلشناسى به عنوان استاندارد طلايى به ترتيب . 1.

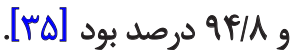

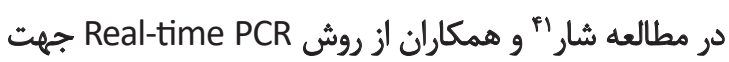

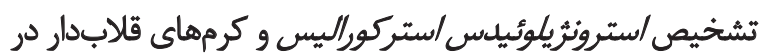

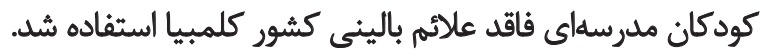

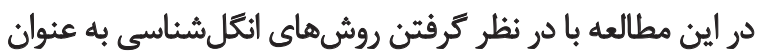

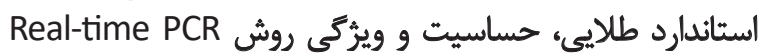

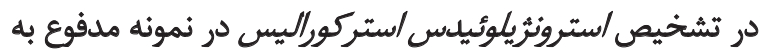

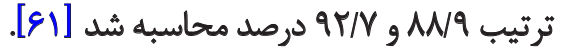

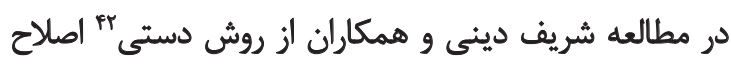

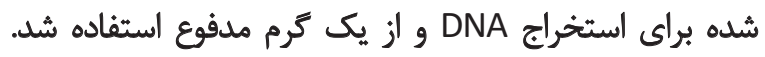

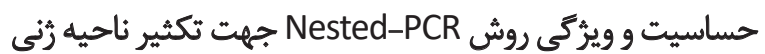

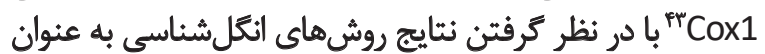

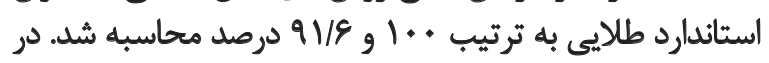

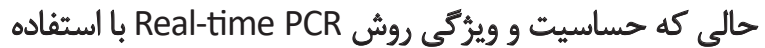

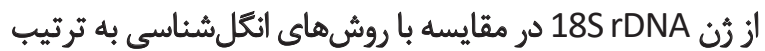

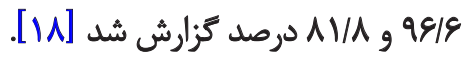

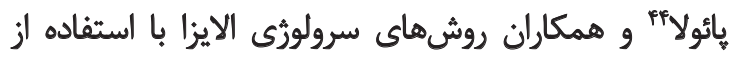

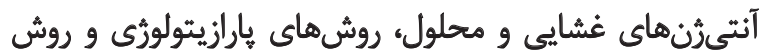
ا Real-time PCR

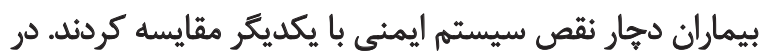

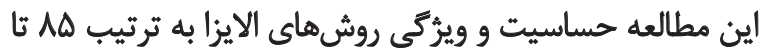

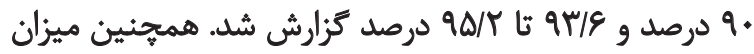

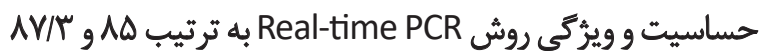
درصد محاسبه شد [عبت.

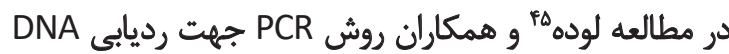

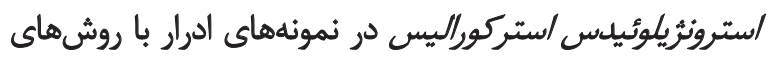

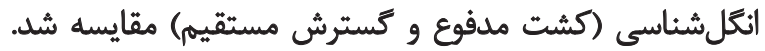

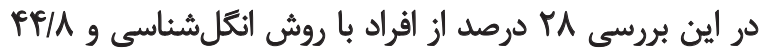

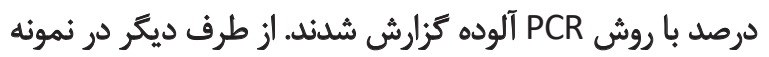

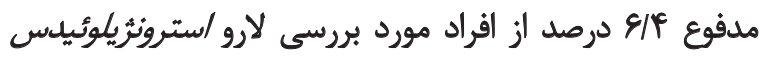

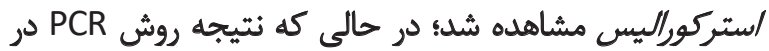

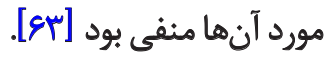

\section{بحث و نتئجه كَيرى}

با افزايش روزافزون مبتلايان به نقص سيستم ايمنى در سراسر

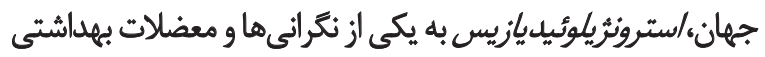

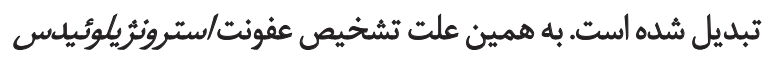




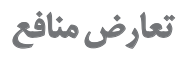

بنابر اظهار نويسند

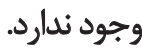

$$
\text { تشيكر و قدرواني }
$$

از سركار خانم دكتر عشرت بيكم كيا عضو هيئتعلمى دانشكاه

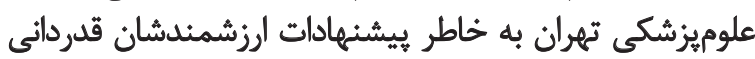

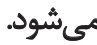




\section{References}

[1] Olsen A, van Lieshout L, Marti H, Polderman T, Polman K, Steinmann P, et al. Strongyloidiasis-the most neglected of the neglected tropical diseases? Trans R Soc Trop Med Hyg. 2009; 103(10):967-72. [DOI:10.1016/j.trstmh.2009.02.013] [PMID]

[2] Gillespie SH, Pearson RD, editors. Principles and practice of clinical parasitology. $1^{\text {st }}$ ed. Hoboken, NJ: Wiley; 2001. [DOI:10.1002/0470842504]

[3] Ericsson CD, Steffen R, Siddiqui AA, Berk SL. Diagnosis of Strongyloides stercoralis infection. Clin Infect Dis. 2001; 33(7):10407. [DOI:10.1086/322707] [PMID]

[4] Keiser PB, Nutman TB. Strongyloides stercoralis in the immunocompromised population. Clin Microbiol Rev. 2004; 17(1):208-17. [DOI:10.1128/CMR.17.1.208-217.2004] [PMID] [PMCID]

[5] Carvalho EM, Da Fonseca Porto A. Epidemiological and clinical interaction between HTLV-1 and Strongyloides stercoralis. Parasite Immunol. 2004; 26(11-12):487-97. [DOI:10.1111/j.01419838.2004.00726.x] [PMID]

[6] Marchi Blatt J, Cantos GA. Evaluation of techniques for the diagnosis of Strongyloides stercoralis in human immunodeficiency virus (HIV) positive and HIV negative individuals in the city of Itajai, Brazil. Braz J Infect Dis. 2003; 7(6):402-8. [DOI:10.1590/S1413-86702003000600008] [PMID]

[7] Hafizi MM, Samoorian S. Fatal strongyloidiasis following massive corticosteroid therapy. Acta Med Iran. 1985; 27(1-4):71-8. http://acta.tums.ac.ir/index.php/acta/article/view/187

[8] Schär F, Trostdorf U, Giardina F, Khieu V, Muth S, Marti H, et al. Strongyloides stercoralis: Global distribution and risk factors. PLoS Negl Trop Dis. 2013; 7(7):e2288. [DOI:10.1371/journal. pntd.0002288] [PMID] [PMCID]

[9] Sharifdini M, Kia EB, Ashrafi K, Hosseini M, Mirhendi H, Mohebali M, et al. An analysis of clinical characteristics of Strongyloides stercoralis in 70 indigenous patients in Iran. Iran J Parasitol. 2014; 9(2):155-62. [PMID] [PMCID]

[10] Ashrafi K, Tahbaz A, Rahmati B. Strongyloides stercoralis: The most prevalent parasitic cause of eosinophilia in Gilan Province, Northern Iran. Iran J Parasitol. 2010; 5(3):40-7. [PMID] [PMCID]

[11] Kia EB, Mahmoudi M, Zahabiun F, Meamar AR. An evaluation on the efficacy of agar plate culture for detection of Strongyloides stercoralis. Iran J Parasitol. 2007; 2(1):29-34. http://ijpa. tums.ac.ir/index.php/ijpa/article/view/15

[12] Keyhani A. Prevalence of intestinal parasites with an emphasis on the diagnosis of Strongyloides stercoralis in the north and northwest of Khuzestan province. [MSc. thesis]. Tehran: Tehran University of Medical Sciences; 2012. [In Persian]

[13] Saeidinia A, Tavakoli I, Naghipour MR, Rahmati B, Ghavami Lahiji H, Salkhori O, et al. Prevalence of Strongyloides stercoralis and other intestinal parasites among institutionalized mentally disabled individuals in Rasht, Northern Iran. Iran J Parasitol. 2016; 11(4):527-33. [PMID] [PMCID]
[14] Sharifdini M, Ghanbarzadeh L, Barikani A, Saraei M. Prevalence of intestinal parasites among rural inhabitants of Fouman, Guilan Province, Northern Iran with emphasis on Strongyloides stercoralis. Iran J Parasitol. 2020; 15(1):91-100. http:// ijpa.tums.ac.ir/index.php/ijpa/article/view/2841

[15] Rafiei R, Rafiei A, Rahdar M, Keikhaie B. Seroepidemiology of Strongyloides stercoralis amongst immunocompromised patients in southwest Iran. Parasite Epidemiol Control. 2016; 1(3):229-32. [DOI:10.1016/j.parepi.2016.08.001] [PMID] [PMA $\mathrm{CID}]$

[16] Esmaeli S, Fakhar M, Gohardehi Sh, Janbabaei Q, Ahmadpour E, Bastani R. [Strongyloides stercoralis infection: Neglected parasitic infection among cancer patients. Pars J Med Sci. 2012; 10(4):13-8. [In Persian] [DOI:10.29252/jmj.10.4.13]

[17] Montes M, Sawhney C, Barros N. Strongyloides stercoralis: There but not seen. Curr Opin Infect Dis. 2010; 23(5):500-4. [DOI:10.1097/QCO.0b013e32833df718] [PMID] [PMCID]

[18] Sharifdini M, Mirhendi H, Ashrafi K, Hosseini M, Mohebali M, Khodadadi $\mathrm{H}$, et al. Comparison of nested polymerase chain reaction and real-time polymerase chain reaction with parasitological methods for detection of Strongyloides stercoralis in human fecal samples. Am J Trop Med Hyg. 2015; 93(6):128591. [DOI:10.4269/ajtmh.15-0309] [PMID] [PMCID]

[19] Sharifdini M, Keyhani A, Eshraghian MR, Beigom Kia E. Molecular diagnosis of strongyloidiasis in a population of an endemic area through nested-PCR. Gastroenterol Hepatol Bed Bench. 2018; 11(1):68-74. [PMID] [PMCID]

[20] van der Feltz M, Slee PHTJ, van Hees PAM, Tersmette M. Strongyloides stercoralis infection: How to diagnose best? Neth J Med. 1999; 55(3):128-31. [DOI:10.1016/S03002977(99)00070-4]

[21] Uparanukraw P, Phongsri S, Morakote N. Fluctuations of larval excretion in Strongyloides stercoralis infection. Am J Trop Med Hyg. 1999; 60(6):967-73. [DOI:10.4269/ajtmh.1999.60.967] [PMID]

[22] Intapan PM, Maleewong W, Wongsaroj T, Singthong S, Morakote N. Comparison of the quantitative formalin ethyl acetate concentration technique and agar plate culture for diagnosis of human strongyloidiasis. J Clin Microbiol. 2005; 43(4):19323. [DOI:10.1128/JCM.43.4.1932-1933.2005] [PMID] [PMCID]

[23] Anamnart W, Pattanawongsa A, Intapan PM, Maleewong W. Factors affecting recovery of Strongyloides stercoralis larvae: An approach to a newly modified formalin-ether concentration technique for diagnosis of strongyloidiasis. J Clin Microbiol. 2010; 48(1):97-100. [DOI:10.1128/JCM.01613-09] [PMID] [PMCID]

[24] Sukhavat K, Morakote N, Chaiwong P, Piangjai S. Comparative efficacy of four methods for the detection of Strongyloides stercoralis in human stool specimens. Ann Trop Med Parasitol. 1994; 88(1):95-6. [DOI:10.1080/00034983.1994.11812843] [PMID]

[25] Koga K, Kasuya S, Ohtomo H. How effective is the agar plate method for Strongyloides stercoralis? J Parasitol. 1992; 78(1):155-6. [DOI:10.2307/3283707] [PMID] 
[26] Buonfrate D, Formenti F, Perandin F, Bisoffi Z. Novel approaches to the diagnosis of Strongyloides stercoralis infection. Clin Microbiol Infect. 2015; 21(6):543-52. [DOI:10.1016/j. cmi.2015.04.001] [PMID]

[27] Sharifdini M, Derakhshani S, Alizadeh SA, Ghanbarzadeh L, Mirjalali H, Mobedi I, et al. Molecular identification and phylogenetic analysis of human Trichostrongylus species from an endemic area of Iran. Acta Trop. 2017; 176:293-9. [DOI:10.1016/j.actatropica.2017.07.001] [PMID]

[28] Sharifdini M, Ghanbarzadeh L, Kouhestani-Maklavani N, Mirjalali $\mathrm{H}$, Saraei M. Prevalence and molecular aspects of human hookworms in Guilan Province, Northern Iran. Iran J Parasitol. 2017; 12(3):374-81. http://ijpa.tums.ac.ir/index.php/ijpa/article/view/1768

[29] Sharifdini M, Heidari Z, Hesari Z, Vatandoost S, Kia EB. Molecular phylogenetics of Trichostrongylus species (Nematoda: Trichostrongylidae) from humans of Mazandaran Province, Iran. Korean J Parasitol. 2017; 55(3):279-85. [DOI:10.3347/ kjp.2017.55.3.279] [PMID] [PMCID]

[30] Silva MLS, Ines EJ, Souza JN, Souza ABS, Dias VMS, Oliveira $L N$, et al. Influence of parasite load on the diagnosis and occurrence of eosinophilia in alcoholic patients infected with Strongyloides stercoralis. J Helminthol. 2019; 93(1):21-5. [DOI:10.1017/S0022149X17001110] [PMID]

[31] Muller R, editor. Worms and human disease. Wallingford: CABI Publishing; 2002. [DOI:10.1079/9780851995168.0000]

[32] Requena-Méndez A, Chiodini P, Bisoffi Z, Buonfrate D, Gotuzzo $E$, Muñoz J. The laboratory diagnosis and follow up of strongyloidiasis: A systematic review. PLoS NegI Trop Dis. 2013; 7(1):e2002. [DOI:10.1371/journal.pntd.0002002] [PMID] [PMCID]

[33] Ines Ede J, Souza JN, Santos RC, Souza ES, Santos FL, Silva ML, et al. Efficacy of parasitological methods for the diagnosis of Strongyloides stercoralis and hookworm in faecal specimens. Acta Trop. 2011; 120(3):206-10. [DOI:10.1016/j.actatropii ca.2011.08.010] [PMID]

[34] Khieu V, Schar F, Marti H, Sayasone S, Duong S, Muth S, et al. Diagnosis, treatment and risk factors of Strongyloides stercoralis in schoolchildren in Cambodia. PLoS Negl Trop Dis. 2013; 7(2):e2035. [DOI:10.1371/journal.pntd.0002035] [PMID] [PMA CID]

[35] Rayan HZ, Soliman RH, Galal NM. Detection of Strongyloides stercoralis in fecal samples using conventional parasitological techniques and real-time PCR: A comparative study. Parasitologists United Journal. 2012; 5(1):27-34. https://www.researchgate.net/publication/256088210

[36] John DT, Petri WA. Markell and Voge's medical parasitology. 9th ed. St. Louis: Saunders Elsevier; 2006. https://books.google.com/books?id=-QSZD783cdsC\&dq

[37] Goka AK, Rolston DD, Mathan VI, Farthing MJ. Diagnosis of Strongyloides and hookworm infections: Comparison of faecal and duodenal fluid microscopy. Trans R Soc Trop Med Hyg. 1990; 84(6):829-31. [DOI:10.1016/0035-9203(90)90098-Y]

[38] Ghoshal UC, Alexender G, Ghoshal U, Tripathi S, Krishnani N. Strongyloides stercoralis infestation in a patient with se- vere ulcerative colitis. Indian J Med Sci. 2006; 60(3):106-10. [DOI:10.4103/0019-5359.22761] [PMID]

[39] Gutierrez Y. Diagnostic pathology of parasitic infections with clinical correlations. New York: Oxford University Press; 2000. https://books.google.com/books?id=oKSEhVMVrJ4C\&dq

[40] Neva FA, Gam AA, Maxwell C, Pelletier LL. Skin test antigens for immediate hypersensitivity prepared from infective larvae of Strongyloides stercoralis. Am J Trop Med Hyg. 2001; 65(5):567-72. [DOI:10.4269/ajtmh.2001.65.567] [PMID]

[41] Sato Y, Toma H, Kiyuna S, Shiroma Y. Gelatin particle indirect agglutination test for mass examination for strongyloidiasis. Trans R Soc Trop Med Hyg. 1991; 85(4):515-8. [DOI:10.1016/0035-9203(91)90240-Y]

[42] Boscolo M, Gobbo M, Mantovani W, Degani M, Anselmi $\mathrm{M}$, Monteiro $\mathrm{GB}$, et al. Evaluation of an indirect immunofluorescence assay for strongyloidiasis as a tool for diagnosis and follow-up. Clin Vaccine Immunol. 2007; 14(2):129-33. [DOI:10.1128/CVI.00278-06] [PMID] [PMCID]

[43] Page WA, Dempsey K, McCarthy JS. Utility of serological follow-up of chronic strongyloidiasis after anthelminthic chemotherapy. Trans R Soc Trop Med Hyg. 2006; 100(11):1056-62. [DOI:10.1016/j.trstmh.2005.12.006] [PMID]

[44] Levenhagen MA, Costa-Cruz JM. Update on immunologic and molecular diagnosis of human strongyloidiasis. Acta Trop. 2014; 135:33-43. [DOI:10.1016/j.actatropica.2014.03.015] [PMID]

[45] Mota-Ferreira DML, Goncalves-Pires MdRF, Júnior Áf, Sopelete MC, Abdallah VOS, Costa-Cruz JM. Specific IgA and IgG antibodies in paired serum and breast milk samples in human strongyloidiasis. Acta Trop. 2009; 109(2):103-7. [DOI:10.1016/j.actatropica.2008.09.023] [PMID]

[46] Koosha S, Fesharaki M, Rokni MB. Comparison of enzymelinked immunosorbent assay and indirect immunofluorescence assay in the diagnosis of human strongyloidiasis. Indian J Gastroenterol. 2004; 23(6):214-6. [PMID]

[47] Bisoffi Z, Buonfrate D, Sequi $M$, Mejia R, Cimino Ro, Krolewiecki AJ, et al. Diagnostic accuracy of five serologic tests for Strongyloides stercoralis infection. PLoS Negl Trop Dis. 2014; 8(1):e2640. [DOI:10.1371/journal.pntd.0002640] [PMID] [PMCID]

[48] Ramanathan R, Burbelo PD, Groot S, ladarola MJ, Neva FA, Nutman TB. A luciferase immunoprecipitation systems assay enhances the sensitivity and specificity of diagnosis of Strongyloides stercoralis infection. J Infect Dis. 2008; 198(3):444-51. [DOI:10.1086/589718] [PMID] [PMCID]

[49] Gonzaga HT, Ribeiro VS, Feliciano ND, Manhani MN, Silva DA, Ueta MT, et al. IgG avidity in differential serodiagnosis of human strongyloidiasis active infection. Immunol Lett. 2011; 139(1-2):87-92. [DOI:10.1016/j.imlet.2011.05.006] [PMID]

[50] Biggs BA, Caruana S, Mihrshahi S, Jolley D, Leydon J, Chea L, et al. Management of chronic strongyloidiasis in immigrants and refugees: is serologic testing useful? Am J Trop Med Hyg. 2009; 80(5):788-91. [DOI:10.4269/ajtmh.2009.80.788] [PMID] 
[51] Rodrigues RM, de Oliveira MC, Sopelete MC, Silva DA, Campos DM, Taketomi EA, et al. IgG1, IgG4, and IgE antibody responses in human strongyloidiasis by ELISA using Strongyloides ratti saline extract as heterologous antigen. Parasitol Res. 2007; 101(5):1209-14. [DOI:10.1007/s00436-007-0602-z] [PMID]

[52] Marcos LA, Terashima A, Canales M, Gotuzzo E. Update on strongyloidiasis in the immunocompromised host. Curr Infect Dis Rep. 2011; 13:35-46. [DOI:10.1007/s11908-010-0150-z] [PMID]

[53] El-Badry AA. ELISA-based coproantigen in human strongyloidiaisis: A diagnostic method correlating with worm burden. J Egypt Soc Parasitol. 2009; 39(3):757-68. [PMID]

[54] Eamudomkarn C, Sithithaworn P, Kamamia C, Yakovleva A, Sithithaworn J, Kaewkes $S$, et al. Diagnostic performance of urinary IgG antibody detection: A novel approach for population screening of strongyloidiasis. PLoS One. 2018; 13(7):e0192598. [DOI:10.1371/journal.pone.0192598] [PMID] [PMCID]

[55] Rogier van Doorn H, Koelewijn R, Hofwegen H, Gilis H, Wetsteyn JCFM, Wismans PJ, et al. Use of enzyme-linked immunosorbent assay and dipstick assay for detection of Strongyloides stercoralis infection in humans. J Clin Microbiol. 2007; 45(2):438-42. [DOI:10.1128/JCM.01735-06] [PMID] [PMCID]

[56] Pak BJ, Vasquez-Camargo F, Kalinichenko E, Chiodini PL, Nutman TB, Tanowitz HB, et al. Development of a rapid serological assay for the diagnosis of strongyloidiasis using a novel diffraction-based biosensor technology. PLoS Negl Trop Dis. 2014; 8(8):e3002. [DOI:10.1371/journal.pntd.0003002] [PMID] [PMAM CID]

[57] McKeand JB. Molecular diagnosis of parasitic nematodes. Parasitology. 1999; 117(7):87-96. [DOI:10.1017/ S0031182099004096] [PMID]

[58] Repetto SA, Alba Soto CD, Cazorla SI, Tayeldin ML, Cuello S, Lasala MB, et al. An improved DNA isolation technique for PCR detection of Strongyloides stercoralis in stool samples. Acta Trop. 2013; 126(2):110-4. [DOI:10.1016/j.actatropii ca.2013.02.003] [PMID]

[59] Moghaddassani H, Mirhendi H, Hosseini M, Rokni MB, Mowlavi Gh, Kia E. Molecular diagnosis of Strongyloides stercoralis infection by PCR detection of specific DNA in human stool samples. Iran J Parasitol. 2011; 6(2):23-30. [PMID] [PMCID]

[60] Verweij JJ, Canales M, Polman K, Ziem J, Brienen EA, Polderman AM, et al. Molecular diagnosis of Strongyloides stercoralis in faecal samples using real-time PCR. Trans R Soc Trop Med Hyg. 2009; 103(4):342-6. [DOI:10.1016/j.trstmh.2008.12.001] [PMID]

[61] Schar F, Odermatt P, Khieu V, Panning M, Duong S, Muth S, et al. Evaluation of real-time PCR for Strongyloides stercoralis and hookworm as diagnostic tool in asymptomatic schoolchildren in Cambodia. Acta Trop. 2013; 126(2):89-92. [DOI:10.1016/j. actatropica.2012.12.012] [PMID]

[62] de Paula FM, Malta FM, Corral MA, Marques PD, Gottardi $\mathrm{M}$, Meisel DMCL, et al. Diagnosis of Strongyloides stercoralis infection in immunocompromised patients by serological and molecular methods. Rev Inst Med Trop Sao Paulo. 2016; 58:63. [DOI:10.1590/S1678-9946201658063] [PMID] [PMCID]
[63] Lodh N, Caro R, Sofer Sh, Scott A, Krolewiecki AJ, Shiff CJ. Diagnosis of Strongyloides stercoralis: Detection of parasite-derived DNA in urine. Acta Trop. 2016; 163:9-13. [DOI:10.1016/j. actatropica.2016.07.014] [PMID] [PMCID] 